\title{
Redesign de marca com participação de Idosos
}

\section{Brand redesign with the elderly's participation}

DAVIM, Bárbara; Universidade Federal do Rio Grande do Norte

bdavim@gmail.com

SANTA ROSA, José Guilherme; D. Sc; Universidade Federal do Rio Grande do Norte

jguilhermesantarosa@gmail.com

\section{Resumo}

O envelhecimento traz consigo novas demandas, exigindo maior estudo e atuação de diversas áreas do saber a fim de atender o público idoso. O designer, por sua natureza social e multidisciplinar, pode contribuir junto ao usuário idoso na construção de novos significados sobre o que é envelhecer e o que é ser idoso. Para esse estudo exploratório, foi desenvolvido o redesign de uma marca de grupo de idosos com a participação dos próprios membros através de ferramentas do design participativo como painel interativo, diferencial semântico, pesquisa semiestruturada e oficina de desenho. Foi constatado uma grande diferença, com a inserção do usuário idoso no processo, tanto na receptividade, conceituação, padrão estético e principalmente, na capacidade do usuário em se reconhecer e se identificar na marca. Espera-se que, com esse estudo, estudantes e profissionais multidisciplinares nas áreas de ciências sociais, saúde entre outras sejam sensibilizados a pesquisar e trabalhar para e com o público idoso.

Palavras Chave: design; envelhecimento; marca e inclusão.

\begin{abstract}
Ageing brings with itself new demands, requiring more study and activities from various segments to assist the elderly public. The designer, due their social and multidisciplinary nature, can help together with the elderly user to build new meanings. For the following exploratory study, an elderly group's brand has been redesigned with the participation of its own members through the use of tools from participatory design such as interactive panel, semantic differential scale, semistructured interviews and drawing workshop. A big difference was seen by the inclusion of the elderly user in the process, as much as on receptivity, conceptualization, aesthetic patterns e most importantly, in how much the user recognized and identified themselves on the new brand. Hopefully, with this study, students and professionals might be touched to research and work more for and with the elderly.
\end{abstract}

Keywords: design; ageing; brand and inclusion. 


\section{Introdução}

O conhecido termo "terceira idade" foi primeiro utilizado na França para as pessoas que se aposentaram. A infância é a primeira idade, improdutiva mas capaz de produzir mais tarde; a vida adulta, a segunda produtiva e por fim a terceira idade, "improdutiva" por não poder retribuir da mesma maneira à sociedade. Tal termo e outros eufemismos como "melhor idade", "idade madura" dentre outras, funcionam como máscaras para disfarçar ou suavizar a velhice. Mas como Neri e Freire (2000) afirmam, se reconhecermos as várias realidades e o processo do envelhecimento, não precisamos negar ou temer algo natural.

A experiência de envelhecimento é particular a cada indivíduo graças à influência genética, escolhas e estilo de vida dentre outros fatores (Nagel, 2012), o que explicita novas necessidades como autonomia, mobilidade, acesso a informações, serviços, segurança e saúde preventiva (Secretaria de Direitos Humanos - SDH, 2012.)

Segundo Simões (2016), idosos compõem cerca de $10 \%$ da população atual brasileira e projeta-se que essa porcentagem deve triplicar para cerca de $29,3 \%$ até 2050 . De acordo com o livro "Brasil, uma visão geográfica e ambiental do século XXI" (2016) em 2030 estima-se que a população idosa (cerca de $18 \%$ ) supere a infantil (17,6\%). Por mais que esteja evidenciando-se esse processo de transição populacional, a estrutura de saúde e econômica não está adequada para uma eventual maioria idosa e isso, segundo o relatório citado acima, trará consequência negativas para a qualidade de vida da população.

Munidos dessa realidade, há estudos empíricos voltados para o idoso, porém reforça-se a necessidade de complementá-los através do viés teórico. Isso acontece porque a interação completa de envelhecimento e tecnologia, segundo Mollenkopf (2004), carece de uma visão integral, uma vez que estão em constantes mudanças na sociedade e, como Kepes (2010) alerta, o fato de tanto nos preocupamos com o material e as conquistas tecnológicas faz com que nos esquecemos do idoso produtivo, ativo, feliz e desenvolvido.

Para isso, o designer precisa de uma formação teórica para análise e reflexão dos problemas, uma vez que permite ideias para facilitar a aplicação e complexidade do design e análise dos resultados como afirmado por Lobach (2000) e reafirmado por Moura et al. (2015). Reforçado por Laville e Dionne (1999), o pesquisador pode oferecer significativa contribuição para a sociedade dado que influencia e é influenciado pelo meio contemporâneo, adquirindo assim uma grande responsabilidade social.

\subsection{Design inclusivo para Idosos}

Considerando o aumento na expectativa de vida e as mudanças de papel do envelhecimento, é imperativo discutir o que é ser idoso. Como Camarano (2013) afirma, o "idoso" é vinculado a características biológicas associadas à incapacidade física, cognitiva ou mental. Porém o "idoso", mais que isso, tem significação em várias esferas sociais como família, relacionamentos e trabalho. A partir de certa idade, ganha-se o "status idoso". No entanto, isso não implica necessariamente que todos os maiores de 60 anos compartilhem das características associadas à velhice e acabam por recusar essa classificação. Assim, a sociedade cria moldes 
associados ao idoso e coage de diferentes maneiras para que o "idoso" assuma essas funções, independente das suas características individuais por não entender exatamente o processo de envelhecimento e o que significa ser idoso.

O Design pode facilitar e possibilitar atividades para saúde e bem estar, mas também para aspectos além do físico como o espiritual, social, cultural e demais esferas relevantes para a qualidade de vida e envelhecimento saudável e ativo do idoso. Nisso, Design torna-se uma ferramenta de criação e pesquisa em tecnologias assistivas que ajudam a promover autonomia e inclusão social segundo Gomes, Stamato e Santos (2015).

Nessa promoção para melhoria de qualidade de vida do idoso, muito se discute a acessibilidade, compreendido em muitos projetos de design como aquilo que é acessível ou de fácil acesso, inteligível e compreendido por várias pessoas independente de sua condição física, sensorial, cognitiva ou de trabalho. Graças à ausência ou redução de barreiras, a acessibilidade exige que se considere aspectos relacionados ao ambiente e ao estado físico, sensorial ou motor das pessoas para que não dificultem ou impeçam o acesso (MIRANDA e ZISSOU, 2009). Porém, pode-se aproximar em projetos de design, o conceito tal como sugere Sassaki (2010) em seis dimensões:

- Acessibilidade Arquitetônica: o designer pode participar ativamente na ausência ou diminuição de barreiras ambientais e físicas no interior e entorno de espaços inclusive há direcionamentos pelo Centro de Referência do Idoso - CRI e ABNT;

- Acessibilidade Comunicacional: o designer pode ajudar a diminuir ou até mesmo eliminar barreiras de comunicação interpessoal, comunicação escrita e comunicação virtual através da elaboração de interfaces, dispositivos e até mesmo projetos como é o caso de estudantes brasileiros conversando com idosos americanos a fim de melhorar as capacidades linguísticas e fazer companhia um ao outro;

- Acessibilidade Metodológica: o designer pode auxiliar na melhoria ou criação de métodos, técnicas ou processos que podem auxiliar na autonomia;

- Acessibilidade Atitudinal: o designer, através das outras acessibilidades ou até mesmo enquanto mídia, pode auxiliar na redução de preconceitos, estigmas, estereótipos e discriminações.

- Acessibilidade Programática: o designer pode auxiliar a reduzir ou eliminar barreiras embutidas em políticas privadas e públicas, através de ferramentas de implementação e manutenção, como as escadas de gestão.

Com o potencial das diversas esferas até então citadas, mais que um profissional a ser consultado pontualmente, o designer pode abranger além da ergonomia, como pontuado por Mont'Alvão e Damazio (2008), a promoção de experiências prazerosas, a individualização e a customização de produtos e serviços para o idoso.

Sendo autonomia, uma das novas necessidades trazidas com o envelhecimento, Sassaki (2010) define autonomia como o domínio no ambiente físico e social, podendo preservar sua privacidade e dignidade. A autonomia é o resultado da prontidão físico-social pessoal, bem como do ambiente físico-social. Muitas vezes descreve-se e justifica-se projetos que auxiliem na autonomia do usuário, às vezes em se locomover melhor ou não precisar de ajuda externa para realizar alguma ação. Porém, algo que muitas vezes - enquanto designers - não consideramos, é se também proporcionamos independência. 
Independência, por sua vez, é descrita pelo autor supracitado como a capacidade de decidir sem depender de outras pessoas. Isso implica a quantidade e qualidade de informações das quais se dispõe, bem como a prontidão em tomar decisões. Isso, curiosamente, inclui na decisão de solicitar ajuda ou não para realizar algo.

Será que estamos considerando que projetar para o idoso não requer que ele faça tudo sozinho, mas que tenha opções diversas para realizar qualquer atividade que queira e seja amparado para isso? Muitas vezes consideramos um espaço planejado para idoso tentando precaver possíveis acidentes. Não seria um ambiente realmente planejado se o idoso tivesse não tão somente autonomia, mas independência em viver nesse espaço, inclusive sair dele para não se restringir tão somente ao lar?

Porém, o que procura-se trazer em questão para o designer discutir, participar e liderar não é a integração, mas a inclusão do idoso. Inclusão, definida por Sassaki (2010), como a modificação da sociedade que é pré-requisito para qualquer pessoa desenvolver e exercer sua cidadania. Portanto, na posição de designer e cidadão, não devemos nos confortar em projetar para adequar o idoso à sociedade, mas também projetar para nos adequarmos ao idoso.

O designer deve ajudar no processo de adaptação social para incluir o idoso no sistema, bem como fazer com que ele assuma os papéis que quiser na sociedade. Esse processo bilateral consiste no idoso e na sociedade equacionando problemas, pensando juntos sobre soluções e na equiparação de oportunidades (SASSAKI, 2010).

A integração do idoso consiste em uma ideia agora vista como ultrapassada, resumindo a participação do Design pelo utilitarismo. No entanto, não há mais como reduzir o Design apenas a isso.

\subsection{Grupo de Idosos Cotinha Vila}

Sob a responsabilidade de uma empresa privada, Cotinha Vila é um grupo de idosos em Natal, Rio Grande do Norte, formado há 17 anos e consiste em uma iniciativa privada para atividades culturais e de lazer para idosos, clientes de serviços oferecidos pela empresa. Foi solicitado pela empresa um redesign da marca, como ponto inicial para um projeto de longo prazo de reestruturação do grupo Cotinha Vila. Tal solicitação, foi um exemplo prático de como o designer pode ser agente em ações junto ao idoso em um contexto local. Por questões de tempo e viabilidade, não foi possível um diagnóstico de demais problemas na área de atuação do design que pudessem ser contempladas além do redesign da marca.

Sousa (2012) reforça que, mais que ser um técnico que executa as ordens de profissionais de comunicação, o designer pode ser uma peça central no processo de conceptualização de marca. A marca deve concretizar a missão do grupo, simbolizando algo que os idosos se identifiquem e pelo qual sintam-se representados. A identidade do criador da marca vigente é desconhecida e não sofreu quaisquer alterações pelos últimos 17 anos. É composta por figuras estilizadas humanas dando mãos em movimento inclinado. Abaixo encontra-se o nome do grupo e o título de "clube da melhor idade" em fonte serifada não identificada. As cores presentes na marca parecem terem sido escolhidas arbitrariamente, possivelmente na tentativa de colorir a marca e oferecer uma informalidade. 
Figura 1 - Marca antiga do Cotinha Vila

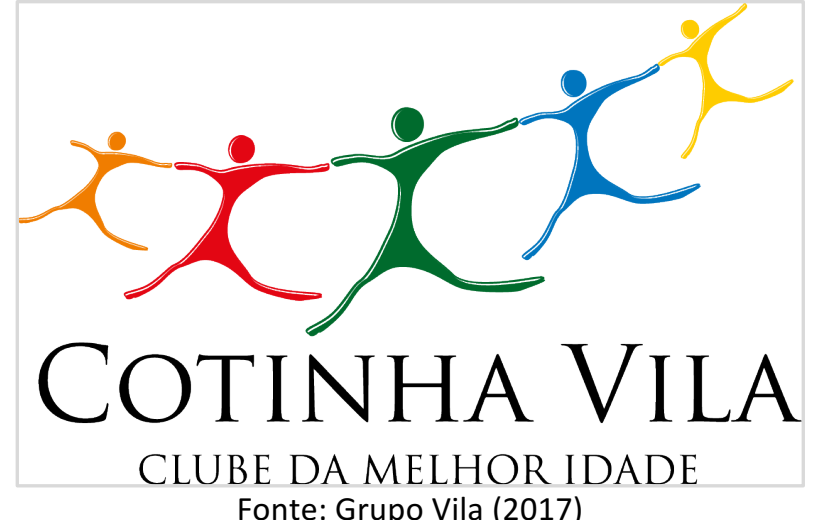

Fonte: Grupo Vila (2017)

\section{Métodos e técnicas}

No primeiro processo de criação, conhecido para esse estudo como Corporativo, as ferramentas escolhidas para a concepção foram:

Briefing simples: lista desenvolvida para melhor compreender e atender ao que o cliente procura e necessita. As perguntas consistiam de: objetivo, público-alvo, palavras-chave, prazo, estilo geral e objeções;

Painel inspirativo: ferramenta de visualização para norteamento de conceitos estéticos a se seguir. Como apontado por Burdek (2006), as imagens ajudam a evitar dúvida sobre significados de palavras, enquanto os painéis tornam-se ferramentas para criação e mediação;

MESCRAI: técnica de lista de verificação que incentiva modificações em projetos e ideias. Segundo Baxter (2008), MESCRAI corresponde a sigla de 'Modifique (aumente, diminua), Elimine, Substitua, Combine, Rearranje, Adapte, Inverta'.

Após discussão com a superior imediata do departamento de Marketing, responsável pela criação e atualização de materiais, e o gestor do departamento de Recursos Humanos, responsável pelo processo de reestruturação do grupo, o seguinte briefing (figura 2) foi desenvolvido. 
Figura 2 - Briefing do redesign da marca Cotinha Vila

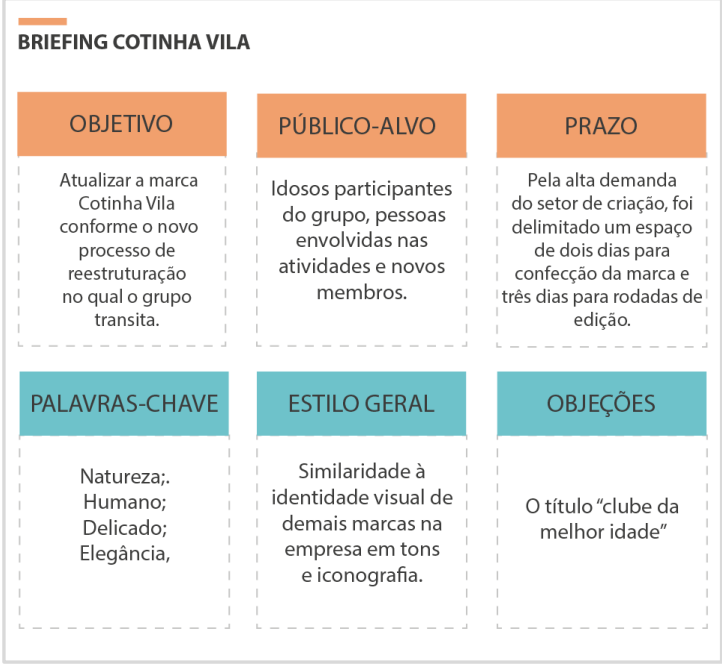

Fonte: Acervo pessoal (2017)

A empresa possui várias marcas sob o guarda-chuva da empresa sede, cada um com sua identidade e posicionamento bem definidos, embora tenham similaridades estéticas como iconografia baseada na natureza. O painel inspirativo foi baseado em marcas de instituições similares para melhor compreensão de como o segmento se apresenta ao mercado e se assemelha às intenções da empresa com a marca. Observou-se a recorrente tema de símbolos relacionados à natureza como folhas e árvores e de tons menos brilhantes. Foram desenvolvidas três opções iniciais de fonte cursiva pelo caráter mais humano e informal.

Durante a rodada de edições, utilizou-se da técnica de MESCRAI, o M para aumento da folha em relação ao título permitindo um espaço negativo cíclico mais harmônico com a letra " $A$ " do primeiro nome e a letra " $V$ " do segundo nome. O C para combinar o símbolo da folha da opção A com a fonte Autumn in November da opção C. E A na adaptação com lettering para melhor legibilidade da letra "O" de Cotinha e maior peso para Gotham medium para melhor legibilidade do subtítulo.

Figura 3 - Marca aprovada pela empresa do Cotinha Vila

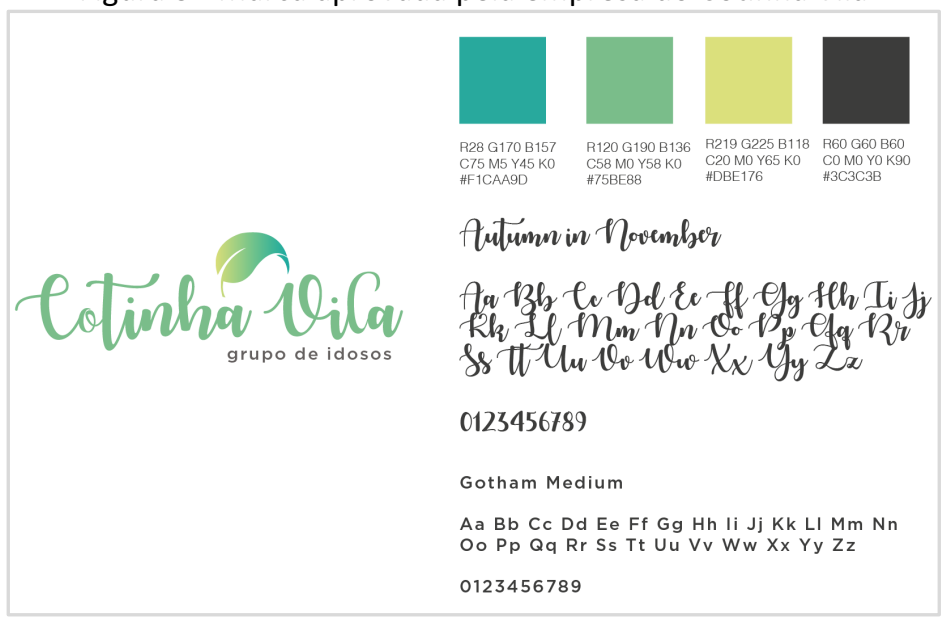

Fonte: Acervo Pessoal (2017) 
Esta última marca, tendo sido a aprovada pelos superiores envolvidos, fez com que a demanda fosse considerada encerrada e outras pautas voltassem à prioridade.

Acreditando no principal objetivo da discussão sobre envelhecimento em se considerar o idoso no processo de criação, questionou-se o porquê de não haver o envolvimento dos participantes do Cotinha Vila na concepção do redesign da marca para eles. Para isso, além da coleta de informações técnicas, era necessário o envolvimento e a participação ativa dos idosos, uma vez que a motivação está relacionada a uma razão político-sociológica, descrito por Santa Rosa e Moraes (2012) como a oportunidade do usuário de influenciar decisões, nesse caso, do seu espaço de lazer.

Com isso, desenvolveu-se então um segundo processo de criação, conhecido para esse estudo como participativo, uma adaptação simplificada da metodologia de Archer (1984), mais voltada às etapas criativas. Segundo Silva et. al. (2017), Archer não enxergava o processo criativo como algo mecânico e metodologias como tal tinham a ambição de melhorar a prática do design no sentido filosófico e social.

Figura 4 - As principais fases da metodologia de Archer (1984)

\begin{tabular}{|c|c|l|}
\hline Fase Analítica & PROGRAMAÇÃO & $\begin{array}{l}\text { Observação } \\
\text { Pensamento Indutivo }\end{array}$ \\
\hline Fase Criativa & COLETA DE DADOS & $\begin{array}{l}\text { Avaliação } \\
\text { Pensamento Dedutivo } \\
\text { Decisão }\end{array}$ \\
\hline Fase Executiva & SÍNTESE & $\begin{array}{l}\text { Descrição } \\
\text { CESENVOLVIMENTO }\end{array}$ \\
\hline
\end{tabular}

Fonte: A autora, adaptado de Lacerda (2012).

Fase Analítica: Coleta de dados para o problema principal, alguns já evidenciados no processo anterior e através de visitas in loco. Foi desenvolvido um novo briefing a partir de uma pesquisa semi-estruturada.

Fase Criativa: fase em que a participação do idoso teve maior impacto na geração de ideias. Foram utilizadas as seguintes técnicas:

Diferencial Semântico: Definido por Osgood e Suci (1952, apud SOUZA, 2014) como uma técnica para medir o posicionamento de indivíduos em relação aos conceitos de escalas bipolares e proporcionar uma avaliação qualitativa e objetiva da relação do idosos com a marca. A técnica original consiste numa escala de sete pontos em que cada ponta possui um binômio antagônico, mas para facilitar a compreensão e a aplicação da técnica, nesse caso, foi simplificado apenas para os binômios e possíveis meios termos.

- Oficina de desenho: técnica para expressão visual e verbal dos idosos sobre possíveis soluções visuais para o redesign. 
- Seleção final das opções de marca pelos participantes.

Fase Executiva: Na metodologia original, esse era o momento em que são definidas as especificações e os materiais junto aos fornecedores para a execução dos projetos. No caso, essa fase vai se resumir na execução e entrega de camisetas com a nova marca aplicada para todos os participantes do grupo ao final do ano.

A pesquisa semi-estruturada foi elaborada para reconhecer quais os objetivos e expectativas dos idosos em relação à marca. A ferramenta se manteve simples e de rápida interação através da mediação da autora porque muitos dos idosos do grupo possuem dificuldade para ler ou escrever ou sentem-se tímidos diante de entrevistas formais. Por isso, a dinâmica foi realizada como uma conversa em grupo, em clima informal, e os idosos já familiarizados com a autora graças a encontros passados. As perguntas-guia para a conversa foram: $O$ que o Cotinha Vila Ihe lembra; Você se sente representado por essa marca; O que você gostaria em uma nova marca.

Sobre o que o significado de Cotinha Vila para eles, palavras escolhidas foram: Aconchegante, Alegria, Bons amigos, Família, Conforto e Diversão. A maioria se sente representada pela marca atual, pois ela representa "união", especialmente pela figuras humanóides de mãos dadas, assim como as cores representam a "alegria".

Um importante ponto levantado é o subtítulo que acompanha o nome do grupo, na atual marca é "clube da melhor idade", o que a maioria estava de acordo e sentia-se representada. Uma minoria expressou porém, que discorda do termo, por não acreditar que a velhice seja a "melhor idade", especialmente pelo desrespeito que sentem diariamente vindo de outras pessoas. Sugestões surgiram então como o "clube da felicidade", "clube da alegria" ou "idade feliz". Alguns manifestaram que dependem "da cara" de uma nova marca para realmente se posicionarem. A partir das respostas foi possível a formulação de um novo briefing conforme figura Figura 5.

Figura 5 - Briefing do redesign da marca Cotinha Vila a partir da resposta dos participantes.

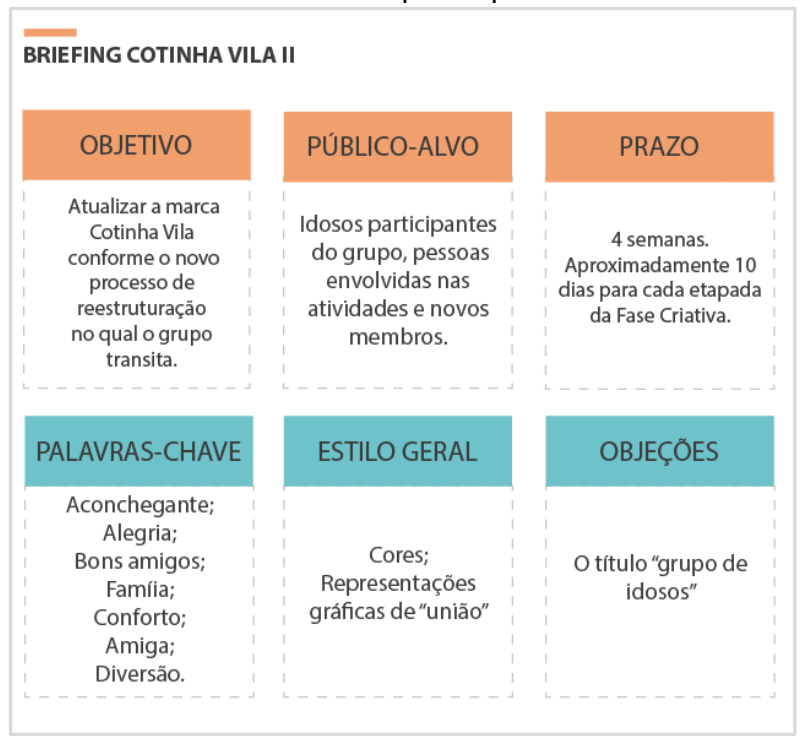

Fonte: Acervo pessoal (2017) 
Para a aplicação do diferencial semântico, a autora selecionou 16 características bipolares, baseado em observações e conversas com os idosos, que pudessem abranger um espectro amplo o suficiente para que os idosos escolhessem de acordo com a sua relação com a atual marca. Uma das dificuldades da técnicas é justamente a seleção das palavras (no caso, imagens) que tornam a interpretação mais clara para os participantes e permitem a autora uma interpretação mais qualitativa da impressão dos participantes. Foram escolhidas imagens correspondentes para cada característica impressa e mostrada, um par por vez, para os idosos escolherem em uma dinâmica conjunta.Os binômios foram: Simples - complicado; Quente - frio; Sério - divertido; Feminino masculino; Colorido - preto e branco; Adulto - infantil; Geométrico - orgânico e Moderno - antigo.

Para essa dinâmica, vinte idosos estavam presentes e foram muito receptivos à dinâmica. As respostas do grupo aos binômios que melhor representavam sua percepção da marca atual é indicado pelos círculos azuis, na figura 6. Uma das respostas mais interessantes ocorreu durante a apresentação do binômio "feminino-masculino", em que unanimemente o grupo escolheu "unissex", esta opção sequer oferecida pela autora durante a dinâmica.

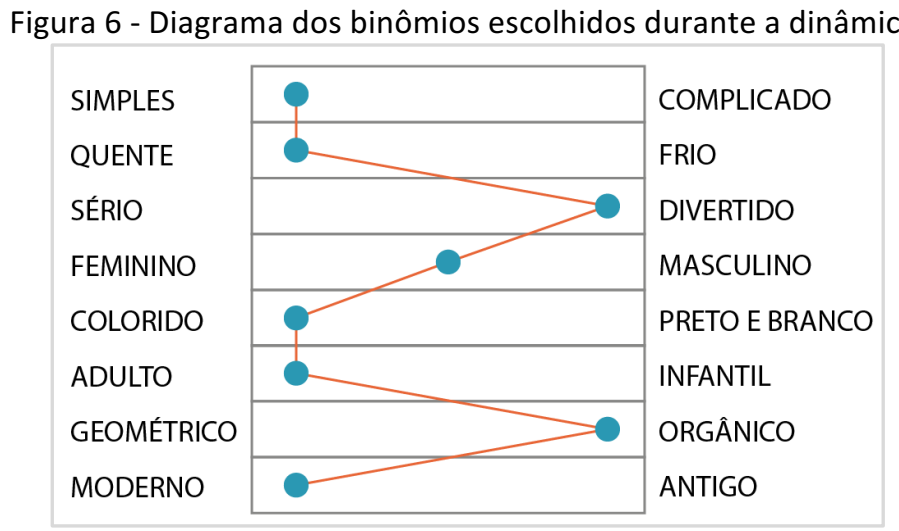

Fonte: Acervo pessoal (2017)

Na etapa seguinte, foram oferecidos materiais (lápis de cor, canetas hidrográficas e giz de cera) para que os idosos desenhassem suas ideias para uma nova marca. A fim de auxiliar na visualização de ideias e conceitos, foram desenvolvidos previamente dois painéis inspirativos a partir das respostas da Fase Analítica.

Para melhor assimilação do conceito de redesenhar uma marca, foi anunciado que a partir do redesign colaborativo, a primeira aplicação prática da nova marca seria em uma camiseta que todos receberão na primeira reunião de 2018 do grupo. Essa aplicação foi especialmente pensada como um retorno à imensa colaboração dos idosos no andamento da pesquisa. Sabe-se que em muitos contextos, pesquisadores têm tempo e recursos limitados para compartilhar com grupos e muitas vezes isso torna-se uma experiência muito curta, mecanizada e impessoal. Portanto foi importante a aproximação prévia da autora com o grupo, assim como a genuína troca de conhecimentos e experiências e o fato de terem algo físico para guardar ao final do processo.

Assim como as dinâmicas anteriores, os idosos presentes se mostraram bem receptivos para participar como podiam. Alguns, inclusive, se oferecendo para descrever verbalmente suas ideias pela incapacidade de desenhar por questões físicas. 


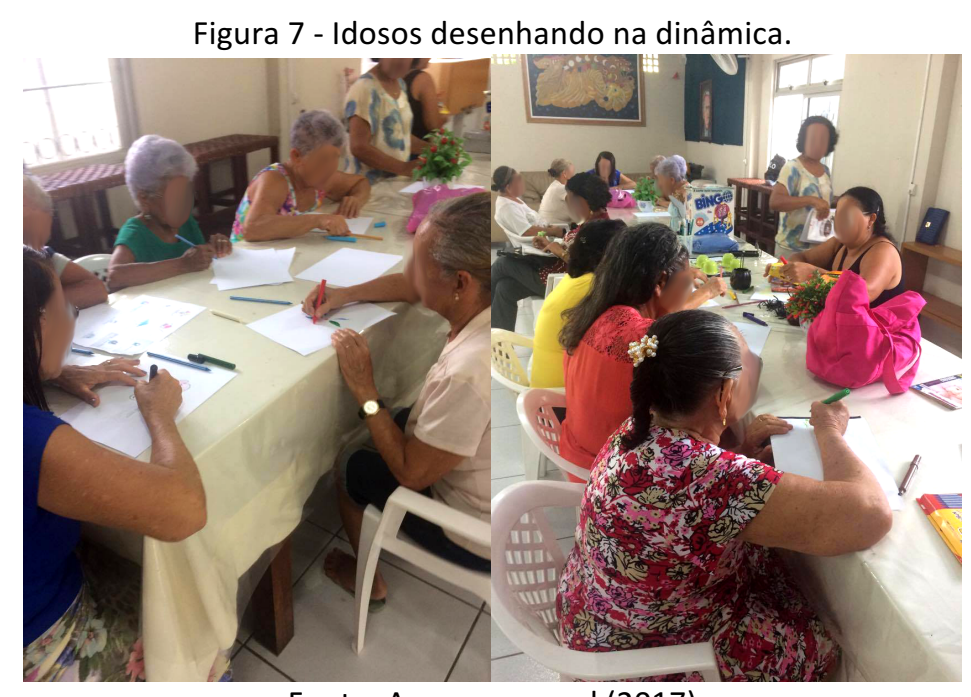

Fonte: Acervo pessoal (2017)

Compreendendo que uma das aplicações da marca era uma estampa de camiseta, dois temas recorrentes nos 20 desenhos recebidos são de natureza (representados por uma flor, árvore ou similar) e união (representados por figuras humanóides de mãos dadas). Foi solicitado aos participantes para assinarem seus nomes como uma maneira de incentivar a autoria, auto reconhecimento e orgulho de sua individualidade através do desenho. Alguns dos desenhos recebidos possuíam assinatura de duplas que se juntaram em colaboração ao desenvolvimento do desenho, muitas vezes porque uma pessoa da dupla tinha problemas de coordenação motora ou algo similar.

Figura 8 - Desenhos dos participantes para a nova marca Cotinha Vila.

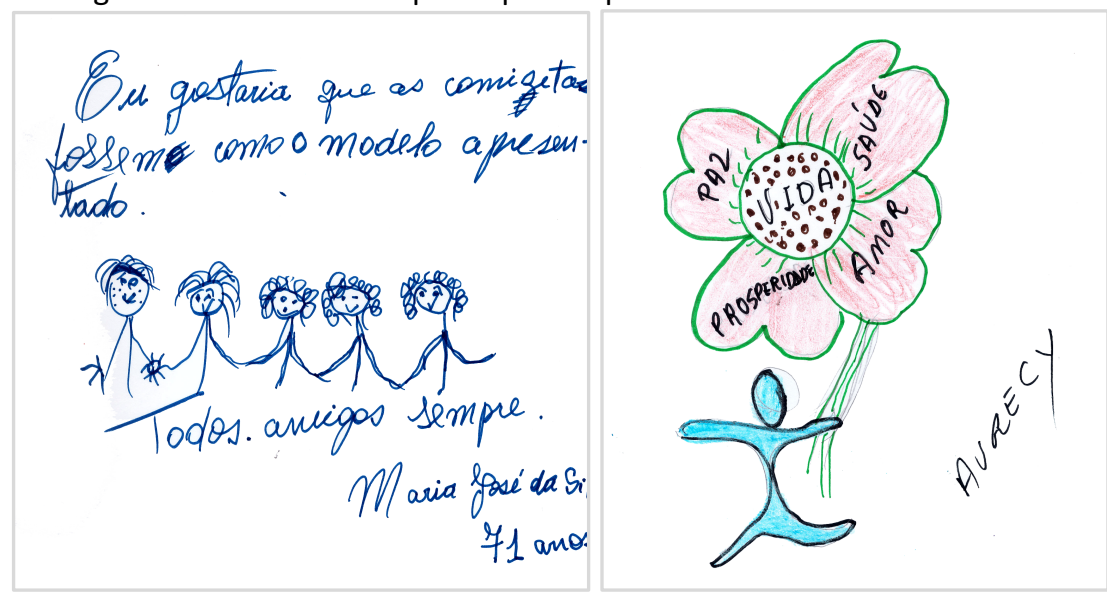

Fonte: Acervo pessoal (2017)

A partir de um maior repertório da percepção verbal e visual dos participantes do grupo em relação à identidade do grupo e a marca, foram feitos estudos até desenvolver quatro opções a serem apresentadas impressas a eles para votação. Surpreendentemente, a escolha unânime se deu pela interpretação dos participantes do desenho. Segundo uma das idosas, "você representou a gente com as mãos, né minha filha, e a gente tá segurando Cotinha Vila (pessoa que inspirou o 
nome do grupo.), Dona A. (responsável pelo grupo) e S. (administradora) que são as luzes das nossas vidas". Tal identificação e ressignificação com o marca excedeu às expectativas, do desenvolvimento, pela identificação imediata dos participantes com o novo símbolo.

Figura 9 - Nova marca Cotinha Vila com paleta de cores e tipografia.

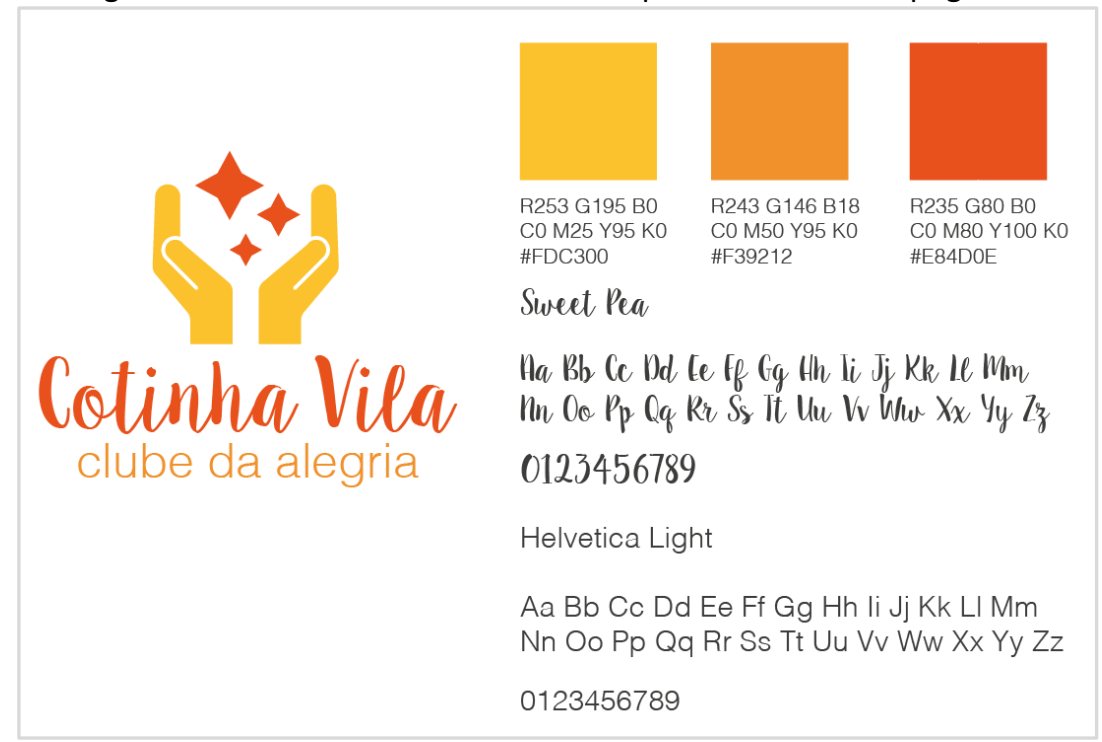

Fonte: Acervo pessoal (2017)

A partir da escolha, foi realizada uma nova dinâmica com binômios para a percepção dos idosos com a nova marca. Os resultados foram muito similares à percepção da antiga marca, o que foi interpretado como positivo pelo fato de os idosos ainda se identificavam com muitos pontos. A única diferença se deu no ponto "infantil" escolhido no binômio infantil-adulto por conta da explicação dos idosos de que o desenho tinha um "ar de criança", mas isso foi recebido positivamente pelo grupo porque não era uma associação direta com a idade dos participantes. Assim como, agora há a possibilidade de uma conexão entre diferentes gerações, uma vez que a marca pode ser bem recebida e quem sabe vestida por filhos, netos entre outros não se restringindo tão somente ao membros acima de 60 anos.

\section{Considerações finais}

As duas marcas, por si, atenderam às demandas exigidas em sua concepção, especialmente descrito pelo briefing. Mas uma notória diferença de concepção e estética envolvida que reforça mais uma vez, a importância do usuário próximo ao processo de criação e significação. Os participantes do Cotinha Vila também foram apresentados à marca desenvolvida no primeiro processo de criação (corporativo), mas não se identificaram por parecer séria demais para o grupo, já que o outro os representava como uma das idosas disse "as mãozinhas é a gente, minha filha".

A empresa também recebeu muito bem a nova marca desenvolvida, tendo não só permitido mas apoiado a elaboração do segundo processo (participativo) desde o começo, 
especialmente pela recepção e engajamento dos idosos. A mesma financiou o desenvolvimentos das camisetas com a nova marca para serem entregues aos participantes, assim como irá agregar a marca do processo participativo aos futuros materiais desenvolvidos para o Cotinha Vila.

Reforça-se a importância da discussão pela transição demográfica ser um fenômeno atual em vários países, incluindo o Brasil, que não está preparado ainda para atender as necessidades básicas da população muito menos as demandas específicas que acompanham o envelhecimento humano. Ressalta-se também que o primeiro passo para atender a alguém é ouvi-lo, o que caracterizou tão fortemente a força por trás do estudo exploratório justamente pela abertura para a palavra e a participação do idoso como agente ativo para resolução dos próprios problemas. A consideração pelo usuário foi importante para a concretização de representação e geração de significado pelo mesmo. Por fim, é importante não só uma aproximação do designer, mas uma sensibilização do mesmo e do público, com o usuário idoso, inspiração e centro da nossa pesquisa, bem como demais áreas envolvidas no estudo do envelhecimento. No papel de pesquisadores devemos compreender o envelhecer, segundo Freire e Sommerhalder (2000), como um presente de alta tecnologia, corrida contra o tempo, produção e renovação de conhecimentos.

\section{Referências}

BAXTER, Mike. Projeto de produto: Guia prático para o design de novos produtos. São Paulo: Edgard Blucher, 2008.

BURDEK, Bernhard E. História, teoria e prática do design de produtos. São Paulo: Edgard Blucher, 2006.

CAMARANO, A.A. Estatuto do Idoso: avanços com contradições. Rio de Janeiro: IPEA, 2013. <Disponível em: http://www.ipea.gov.br/portal/images/stories/PDFs/TDs/td_1840.pdf.> Acesso em: 27 mar. 2017

FREIRE, Sueli Aparecida; SOMMERHALDER, Cinara. Envelhecer nos tempos modernos. In: NERI, Anita Liberalesso; FREIRE, Sueli Aparecida (Org.). E por falar em boa velhice. Campinas: Papirus, 2000. p. 125-134.

GOMES, Danila; STAMATO, Claudia; SANTOS, Luis Claudio Belmonte dos; "A Inclusão Social Por Meio Do Design E Da Ergonomia: Dispositivo De Input De Informação Para Pessoas Com Deficiência Nos Membros Superiores", p. 507-518 . In: Anais do 15ํㅡㄹodesign \& Usihc. São Paulo: Blucher, 2015.

KEPES, György. A função no Design Moderno. In: BEIRUT, Michael et al (Org.). Textos Clássicos do Design Gráfico. São Paulo: Wmf Martins Fontes, 2010. p. 104-111.

LACERDA, A. P. DE. Pioneiros Dos Métodos De Projeto (1962-1973): Redes Na Gênese Da Metodologia Do Design Redes Na Gênese Da Metodologia Do Design. [s.I.] UFRGS Universidade Federal do rio Grande do Sul, 2012.

LAVILLE, C.; DIONNE, J. A construção do saber: manual de metodologia da pesquisa em ciências humanas. Porto Alegre: Editora Artes Médicas Sul Ltda.; Belo Horizonte: Editora UFMG. 1999. 
LÖBACH, Bernd. Design industrial: bases para a configuração dos produtos industriais. São Paulo: Ed. Edgard Blücher, 2001.

MIRANDA, Andréa da Silva; ZISSOU, Alex de Jesus. Considerações sobre Acessibilidade e Usabilidade em Ambientes Hipermídia. In: ULBRICHT, Vania Ribas; PEREIRA, Alice Theresinha Cybis (Org.). Hipermídia: Um Desafio da Atualidade. Florianópolis: Pandion, 2009. p. 15-29.

MOLLENKOPF, Heidrun. Aging and Technology - Social Science Approaches. In: BURDICK, David C.; KWON, Sunkyo (Org.). Gerotechnology: Research and Practice in Technology and Aging. Nova York: Springer Publishing Company, 2004. p. 54-64.

MONT'ALVÃO, Claudia. Hedonomia, Ergonomia afetiva: afinal, do que estamos falando? In: MONT'ALVÃO, Claudia; DAMAZIO, Vera (Org.). Design Ergonomia Emoção. Rio de Janeiro: Mauad X, 2008. p. 19-30.

MOURA, Mônica et al. Design Contemporâneo: pesquisas interdisciplinares. In: PASCHOARELLI, Luis Carlos; SALCEDO, Rosio Fernández Baca (Org.). Interação: Panorama das Pesquisas em Design, Arquitetura e Urbanismo. Bauru: Canal 6, 2015. p. 139-148.

NAGEL, Irene E. Cada Um Envelhece de Um Jeito. 2012. Disponível em:

<http://www2.uol.com.br/vivermente/noticias/cada_um_envelhece_de_um_jeito.html >. Acesso em: 21 fev. 2017.

NERI, Anita Liberalesso; FREIRE, Sueli Aparecida. Qual é a Idade da Velhice. In: NERI, Anita Liberalesso; FREIRE, Sueli Aparecida (Org.). E por falar em boa velhice. Campinas: Papirus, 2000. p. 7-19.

PEREIRA, Renata de Andrade Marques; Damazio, Vera. Design e Envelhecimento: um estudo sobre ações projetuais para a construção de uma nova velhice. Rio de Janeiro, 2014. 103p. Dissertação de Mestrado - Departamento de Artes e Design, Pontifícia Universidade Católica do Rio de Janeiro

SANTA ROSA, J. G; MORAES, A. Design Participativo - técnicas de inclusão de usuários no processo de ergodesign de interfaces. Rio de Janeiro: Rio Books, 2012.

SASSAKI, Romeu Kazumi. Inclusão: Construindo uma sociedade para todos. 8. ed. Rio de Janeiro: Wva, 2010.

SECRETARIA DE DIREITOS HUMANOS. Dados sobre o envelhecimento no Brasil. Brasília: Secretaria Nacional de Promoção Defesa dos Direitos Humanos, 2012. Disponível em:

<http://www.sdh.gov.br/assuntos/pessoa-idosa/dados-

estatisticos/DadossobreoenvelhecimentonoBrasil.pdf>. Acesso em: 19 fev. 2017.

SILVA, Flavio Barbosa da et al. Bruce Archer: Método Sistemático para Designers. 2017.

Disponível em: <http://www.vigha.com/wp-content/uploads/2017/06/Artigo-Bruce-Archerfinal.pdf>. Acesso em: 4 nov. 2017.

SIMÕES, Celso Cardoso da Silva. A Relações entre as alterações históricas na dinâmica demográfica brasileira e os impactos decorrentes do processo de envelhecimento da população. 


\section{Artigo Completo}

Rio de Janeiro: IBGE, Coordenação de População e Indicadores Sociais, 2016. Disponível em: <http://biblioteca.ibge.gov.br/visualizacao/livros/liv98579.pdf>. Acesso em: 19 fev. 2017.

SOUSA, Álvaro. Uma metodologia de avaliação de marcas para apoiar a decisão do designer na hora da conceptualização e desenho. 2 CIDAG -Desafios conceptuais para o Design e a Produção Gráfica. Proceedings book. Lisboa, 2012. p.196-199.

SOUZA, Ivana dos Santos de Lima e. Semantikos: Proposta de interfaces para aplicativo mediador de técnica de diferencial semântico em mobile tablet. 2014. 110 f. Dissertação (Mestrado) - Curso de Design, Universidade Federal do Rio Grande do Norte, Natal, 2014 